\title{
Acknowledgment of Reviewers for v37
}

As the editor of Contemporary Jewry, I count on the informed judgment of those of you who volunteer to serve as peer reviewers for articles in your area of expertise. Your advice is essential to us in deciding whether to accept a paper for publication and invaluable to authors when undertaking revisions. In a double-blind review process, at least three experts contribute valuable comments about each paper published in COJE, making it possible to publish high quality work in a timely manner. Here is a list of reviewers who volunteered their time and expertise for $\mathrm{v} 37$ of the journal. Do note that any omission is due to human oversight and unintentional. Thank you, reviewers, for your time, energy and commitment to the journal!

Attias-Donfut, Claudine

Bahloul, Joelle

Bronner, Simon

Bruder, Edith

Carr, C. Lynn

Cohen, Jeffrey

Danan, Ariel

Ferziger, Adam

Graetz, Naomi

Helmreich, William

Horowitz, Bethamie

Kadushin, Charles

Katz, Ethan

Kaufmann, David

Kim, Helen K.

Krasner, Jonathan

Kritzman, Lawrence

Marker, David

\author{
McGinity, Keren \\ Milligan, Amy \\ Mosbah-Natanson, Sebastien \\ Nordmann, Sophie \\ Obadia, Lionel \\ Parfitt, Tudor \\ Patt, Avinoam J. \\ Phillips, Bruce A. \\ Prell, Riv-Ellen \\ Scioldo-Zurcher, Yann \\ Shain, Michelle \\ Sigalow, Emily \\ Stillman, Norman \\ Weinfeld, Morton \\ Weill, Georges \\ Wetzel, Julie \\ Zerubavel, Yael \\ Zwilling, Anne Laure
}

Should you be interested in becoming a reviewer for Contemporary Jewry, please send me an email with your name, affiliation, and areas of expertise (hartman@rowan.edu). 